Graphical Abstract (for review)

Graphical Abstract
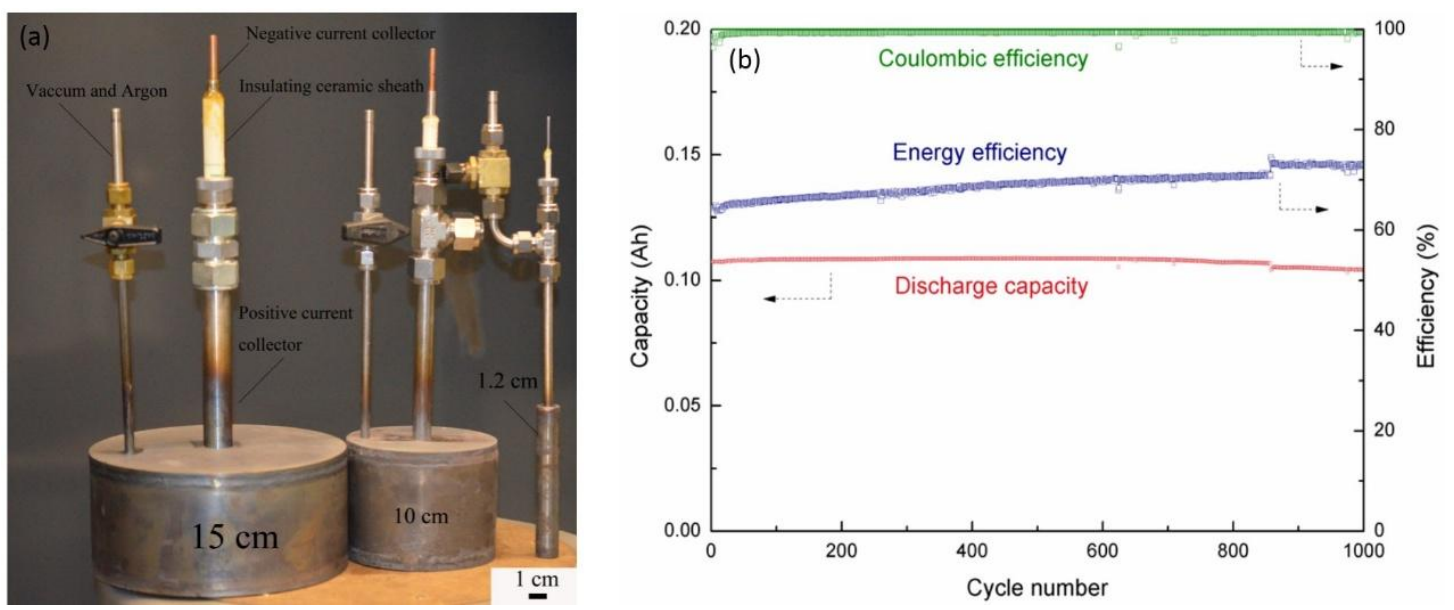


\title{
Self-healing Li-Bi liquid metal battery for grid-scale energy storage
}

\author{
Xiaohui Ning ${ }^{1}$, Satyajit Phadke ${ }^{2}$, Brice Chung, Huayi Yin, Paul Burke, and Donald R. Sadoway \\ Department of Materials Science and Engineering \\ Massachusetts Institute of Technology \\ 77 Massachusetts Avenue \\ Cambridge, Massachusetts, 02139-4307 \\ U.S.A.
}

\begin{abstract}
In an assessment of the performance of a $\mathrm{Li}|\mathrm{LiCl}-\mathrm{LiF}| \mathrm{Bi}$ liquid metal battery, increasing the current density from 200 to $1250 \mathrm{~mA} \mathrm{~cm}^{-2}$ results in a less than $30 \%$ loss in specific discharge capacity at $550^{\circ} \mathrm{C}$. The charge and discharge voltage profiles exhibit two distinct regions: one corresponding to a $\mathrm{Li}-\mathrm{Bi}$ liquid alloy and one corresponding to the two-phase mixture of $\mathrm{Li}-\mathrm{Bi}$ liquid alloy and the intermetallic solid compound, $\mathrm{Li}_{3} \mathrm{Bi}$. Full cell prototypes of $0.1 \mathrm{Ah}$ nameplate capacity have been assembled and cycled at $3 \mathrm{C}$ rate for over a 1000 cycles with only $0.004 \%$ capacity fade per cycle. This is tantamount to retention of over $85 \%$ of original capacity after 10 years of daily cycling. With minimal changes in design, cells of 44.8 Ah and 134 Ah capacity have been fabricated and cycled at $\mathrm{C} / 3$ rate. After a hundred cycles and over a month of testing, no capacity fade is observed. The coulombic efficiency of $99 \%$ and energy efficiency of $70 \%$ validate the ease of scalability of this battery chemistry. Post mortem cross sections of the cells in various states of charge demonstrate the total reversibility of the $\mathrm{Li}_{3} \mathrm{Bi}$ solid phase formed at high degrees of lithiation.
\end{abstract}

current affiliations

1. Center for Advancing Materials Performance from the Nanoscale (CAMP-Nano), State Key 
Laboratory for Mechanical Behavior of Materials, Xi'an Jiaotong University, Xi'an 710049, People's Republic of China.

2. Mechanical and Aerospace Engineering Department, Princeton University, Princeton, NJ, U.S.A. 


\section{Introduction}

Electric energy storage systems have attracted more and more attention due to the increased deployment of renewable generation, the high capital cost of managing grid peak demands, and large capital investments in grid infrastructure for reliability [1-4]. However, for widespread application, existing well-developed battery technologies struggle to meet all the requirements of durability, high power, roundtrip energy efficiency, and cost. Pumped hydroelectric energy storage, the largest and most mature commercial utility-scale technology is location-dependent and requires an immense capital investment. Compressed air energy storage is also site-dependent. Mechanical flywheels are too expensive for deployment in grid up to now [1]. Lead acid battery meets the cost requirements; however, its limited cycle life (a few hundred cycles) and relatively low efficiency is still an unsolved problem. Sodium-sulfur and sodium-metal halide systems have inherent safety risk due to the thermal and mechanical stability of $\beta^{\prime \prime}$-alumina tubes at battery operating temperatures [5]. Lithium-ion batteries exhibit good performance; however, their high cost and high fade rate detract from widespread use in stationary applications.

Recently, our group developed a novel battery system named liquid metal battery (LMB), which has suitable performance characteristics for deployment as a grid-scale electrochemical energy storage device with long lifetime and low cost $[6,7]$. The liquid metal battery consists of three liquid layers that are segregated on the basis of their mutual immiscibility and differences in density. A liquid metal with low electronegativity and low density forms a layer on the top, another liquid metal with the high electronegativity and high density pools on the bottom, and a molten salt electrolyte with intermediate density floats in between the two metals. We hereby present experimental results on a chemistry based on the LMB concept and demonstrate high 
cyclability and long service lifetime.

Lithium has low melting point $\left(180.5^{\circ} \mathrm{C}\right)$ and is the least soluble alkali or alkaline-earth metal in molten salts $[8,9]$, which makes it an attractive LMB negative electrode. In the 1960s, Argonne National Laboratory performed fundamental thermodynamic investigations of various electrode couples including $\mathrm{Li}$ or $\mathrm{Na}$ as the negative electrode with $\mathrm{Pb}, \mathrm{Sb}$ or $\mathrm{Bi}$ as the positive electrode, and lithium halide molten salt mixtures or pastes as the electrolyte [10]. Shimotake, Rogers, and Cairns [11] assembled a secondary cell with an negative electrode of liquid Li, a fused LiF-LiCl-LiI eutectic electrolyte immobilized as a rigid paste, and a positive electrode of liquid $\mathrm{Bi}$ or liquid Te. The cell was operated in the temperature range from $380^{\circ} \mathrm{C}$ to $485^{\circ} \mathrm{C}$ at current densities up to $2.2 \mathrm{~A} \mathrm{~cm}^{-2}$ during which a nominal voltage of $0.6 \mathrm{~V}$ was observed. However, due to the high internal resistance of the paste electrolyte, the cell suffered from a high ohmic drop between the electrodes, which resulted in unacceptably low values of energy efficiency. Based on the e.m.f. measurements of Weppner and Huggins [12] and the Li-Bi binary phase diagram [13], the Li-Bi couple attracted our attention as a high-voltage, low-melting system, suitable as a candidate electrode pairing.

In this study, we found that the Li||Bi LMB can be discharged much deeper by allowing a solid intermetallic compound to form in the positive electrode. The formation of this intermetallic compound is fully reversible: upon charging of the battery the intermetallic is fully dissolved and the battery returns to its pristine, fully liquid state.

Prototype cells demonstrating this novel self-healing LMB system of Li-Bi were assembled. Using very minimal changes in the original design, the capacity and size of the batteries were scaled up over 3 orders of magnitude. The low fade rate observed at various prototype capacities is indicative of the high reversibility and ease of scalability of this system, which make it an ideal 
candidate for grid-scale storage.

\subsection{Description of the battery}

The Li\|Bi battery comprises a negative electrode of $\mathrm{Li}$, a molten salt electrolyte (LiCl-LiF), and a positive electrode of $\mathrm{Bi}$. As shown in Fig. 1 (b), during discharge, $\mathrm{Li}$ is oxidized to $\mathrm{Li}^{+}$ $\left(\mathrm{Li} \rightarrow \mathrm{Li}^{+}+\mathrm{e}\right)$ at the negative electrode; $\mathrm{Li}^{+}$dissolves into the electrolyte, and the electron is released into the external circuit. Simultaneously, at the positive electrode $\mathrm{Li}^{+}$ions in the electrolyte are reduced to $\mathrm{Li}$ metal, which alloys with $\mathrm{Bi}\left(\mathrm{Li}^{+}+\mathrm{e} \rightarrow \mathrm{Li}_{\mathrm{Bi}}\right)$. The reverse reactions occur when the battery is charged.

Initially, during discharge, $\mathrm{Li}$ alloys with $\mathrm{Bi}$ forming a single-phase, liquid-metal alloy. Upon further discharge a solid phase is formed. The instant mix of phases in the positive electrode varies with depth of discharge and is graphically depicted in the binary phase diagram in Fig. 1 (a). After the formation of a $52 \% \mathrm{Li}-\mathrm{Bi}$ alloy (follow the red line), a solid $\mathrm{Li}_{3} \mathrm{Bi}$ intermetallic begins to form. As the composition continues to $75 \% \mathrm{Li}$, the amount of solid intermetallic increases until the liquid phase is completely transformed and the positive electrode is fully solid. While discharging between $52 \%$ and $75 \%$, the solid intermetallic forms a layer, whic0h floats at the top of the positive electrode due to its lower density compared to that of liquid Li-Bi alloy (Table 1). Upon charging, the $\mathrm{Li}_{3} \mathrm{Bi}$ layer is gradually consumed until the concentration of $\mathrm{Li}$ is less than $52 \%$, when the system is fully liquid again.

\section{Experimental}

\subsection{Three-electrode experimental set-up}

To study the electrochemical behavior of a single electrode, the three-electrode cell illustrated schematically in Fig. 2a was constructed. Pure Bi served as the working electrode 
(WE) prepared by melting Bi (99.999\%, Alfa Aesar) in a boron nitride (BN, $\left.0.28 \mathrm{~cm}^{2} \times 1.9 \mathrm{~cm}\right)$ crucible (Saint-Gobain Advanced Ceramics, NY, US). The entire melting process was conducted inside a glovebox with an inert argon atmosphere $\left(\mathrm{O}_{2}<0.1 \mathrm{ppm}, \mathrm{H}_{2} \mathrm{O}<0.1 \mathrm{ppm}\right)$ using an induction heater (MTI Corporation, China). A Li-Bi alloy $\left(\mathrm{x}_{\mathrm{Li}}=0.6\right)$ was designed as a reference electrode (RE), which was also prepared in a BN crucible (cross area: $3.6 \mathrm{~cm}^{2}$, dia: $1.9 \mathrm{~cm}$ ) by induction melting pure $\mathrm{Bi}$ and then gradually adding small lumps of Li metal. This reaction is highly exothermic and hence the addition must be done with caution. A Li-Pb alloy $\left(\mathrm{x}_{\mathrm{Li}}=0.4\right)$ was used as a counter electrode (CE), which was prepared in the same way. A eutectic mixture of $\mathrm{LiCl}(70 \mathrm{~mol} \%)$ - $\mathrm{LiF}$ (30 mol\%) served as the electrolyte.

The electrochemical cell components were assembled in a glovebox under an inert $\mathrm{Ar}$ atmosphere. Electrical contact with the electrodes was established by means of tungsten wires (99.95\%, Alfa Aesar), $1 \mathrm{~mm}$ in diameter and $0.5 \mathrm{~m}$ in length, immersed into the electrodes while they were molten. Each electrical lead was insulated from the test vessel by an alumina tube (McDanel Advanced Ceramic Technologies, PA, US). The electrodes were placed inside an alumina crucible, inner dia. of $56 \mathrm{~mm}$ and height of $100 \mathrm{~mm}$. Following the electrode preparation about $140 \mathrm{~g}$ electrolyte was poured over them in the molten form. Then the cell was placed into a stainless steel vacuum chamber. After sealing, the chamber was loaded into a furnace. [14]

\subsection{Assembly of the Li\|Bi battery (0.1 Ah, $20 \mathrm{Ah}, 200 \mathrm{Ah}$ nameplate capacities)}

The three different sized battery prototypes had a very similar design consisting of a cylindrical steel crucible, current collector, current leads, and a cell cap (Fig. 2b and Fig. S1). The diameter of the crucible and the cap were 1.2, 10, and $15 \mathrm{~cm}$ for the 0.1,20, and $200 \mathrm{Ah}$ nameplate capacity cells, respectively. Each cell was fitted with two feedthroughs at the top, one for backfilling with Ar (after welding the top) and the other for inserting the current collector 
(Fig. 2b and S1). Assembly of the prototypes was performed in an Ar-filled glove box $\left(\mathrm{O}_{2}\right.$ and $\left.\mathrm{H}_{2} \mathrm{O}<0.1 \mathrm{ppm}\right)$. The negative current collector was a circular disc made of Ni-Fe foam. The negative electrode was fabricated by immersion of the current collector into a pool of molten Li, which was absorbed by the metal foam. Bi granules (99.5\% purity, Alfa-Aesar) were placed in the bottom of the crucible after which the electrolyte was added, and the negative electrode was placed on the top of the salt. The dimensions and amounts of materials used in different sized cells are shown in Table S1. The inter-electrode gap was fixed as $1 \mathrm{~cm}$ at which distance the IR drop was observed to vary from $0.05-0.12 \mathrm{~V}$.

\subsection{Cell operation and electrochemical characterization}

Assembled cells were moved outside the glovebox, and the cap was welded shut onto the steel crucible. The cells were leak tested and then back filled with Ar prior to the next step. The cell was heated to $80^{\circ} \mathrm{C}$ under vacuum and held for $12 \mathrm{~h}$ in a custom designed furnace, then heated to $250^{\circ} \mathrm{C}$ and held for an additional $12 \mathrm{~h}$ to dry. The cell was backfilled with Ar and heated at a rate of $5^{\circ} \mathrm{C} \min ^{-1}$ to the cell operating temperature of $550^{\circ} \mathrm{C}$.

Galvanostatic cycling for the three-electrode experiment was performed with an Autolab instrument model PGSTAT302N controlled by Nova 1.8 software. At beginning of each electrochemical measurement, the pure $\mathrm{Bi}$ WEs were held at $1.5 \mathrm{~V}$ for $1 \mathrm{~h}$ to ensure consistent initial conditions. Then a constant current density (from $200-1250 \mathrm{~mA} \mathrm{~cm}{ }^{-2}$ ) was forced through the WE to discharge the cell while potential was monitored between WE and CE.

Battery cycling was performed with an Arbin BT-2000 Battery Tester. The full cells were charged and discharged at a rate of $\mathrm{C} / 4,0.35 \mathrm{~V}$ as the lowest discharge voltage and $1.1 \mathrm{~V}$ as the highest charge voltage. The constant current charging step was followed by a constant voltage hold at $1.1 \mathrm{~V}$ until the current dropped below C/20. After the completion of the planned cycling 
procedure, the cells were cooled down to room temperature and sectioned on a cutting saw for post-mortem investigation.

\section{Results and discussion}

\subsection{Kinetic behavior}

In order to investigate the kinetic behavior of the Bi electrode a three-electrode experiment was devised, and the electrode was discharged at different current densities. Pure Bi served as the $\mathrm{WE}, \mathrm{Li}-\mathrm{Pb}$ alloy $(40 \mathrm{~mol} \% \mathrm{Li})$ as the $\mathrm{CE}$, and $\mathrm{Li}-\mathrm{Bi}$ alloy $(60.5 \mathrm{~mol} \% \mathrm{Li})$ as the $\mathrm{RE}(0.7 \mathrm{~V}$ vs. Li(s)). The cell was operated over a wide range of current densities in order to examine how the rate of discharge affects the discharge potential and the specific discharge capacity. The discharge time lines corresponding to $0.2,0.3,0.4,0.75,1.0$, and $1.25 \mathrm{~A} \mathrm{~cm}^{-2}$ are shown in Fig. 3. It can be seen that increasing the current density from $0.2 \mathrm{~A} \mathrm{~cm}^{-2}$ to $1.25 \mathrm{~A} \mathrm{~cm}^{-2}$ results in only $27 \%$ decrease in the capacity of the electrode. The median potential of the discharge curve (vs. Li) decreases from $675 \mathrm{mV}$ to $525 \mathrm{mV}$ in response to an increase in current density from $0.2 \mathrm{~A} \mathrm{~cm}^{-2}$ to $1.25 \mathrm{~A} \mathrm{~cm}^{-2}$.

It is noteworthy that the discharge time line can be divided into two distinct regions, one in which the potential is continuously changing and one in which the potential is constant. These correspond to homogeneous single-phase and heterogeneous two-phase regions, respectively, and are labeled accordingly in Fig 3. As per the phase diagram shown in Fig. 1a, the single-phase region relates to the all-liquid zone where Li alloys with Bi during the early stage of discharge. The two-phase region, where $\mathrm{Li}_{3} \mathrm{Bi}$ (solid) and $\mathrm{Li}-\mathrm{Bi}$ alloy (liquid) co-exist, is encountered later. The potential drops precipitously upon reaching the end of discharge at which point the WE composition is $75 \mathrm{~mol} \% \mathrm{Li}\left(\mathrm{Li}_{3} \mathrm{Bi}\right)$. Since the density of $\mathrm{Li}_{3} \mathrm{Bi}$ is significantly lower than that of $\mathrm{Bi}, \mathrm{Li}_{3} \mathrm{Bi}$ forms on the surface of the $\mathrm{Bi}$ pool. In some systems such as $\mathrm{Ca}-\mathrm{Bi}$, it has been 
observed that the formation of a solid intermetallic at the interface resulted in a sharp decrease in potential [15]. A similar observation is also reported in the Na-Bi system; hence, these cells can be cycled only in the all-liquid region [10]. However, in the Li\|Bi system such a potential decrease associated with the formation of the intermetallic is not observable. This is an indication of fast lithium diffusion through the solid $\mathrm{Li}_{3} \mathrm{Bi}$.

\subsection{Long term cycling}

To investigate the cyclability of the Li||Bi system, a small prototype was assembled. Details about the cell construction, dimensions and electrode masses are summarized in Table S1. A schematic of the cell construction and pictures of an assembled cell are shown in Fig. S1. The cell was galvanostatically cycled at $0.3 \mathrm{~A} \mathrm{~cm}^{-2}(0.33 \mathrm{~A})$, which corresponds to a $3 \mathrm{C}$ rate. The cut-off voltage was set as $1.2 \mathrm{~V}$ for charging and $0.3 \mathrm{~V}$ for discharging. At the end of the discharge step, the composition of the positive electrode was estimated to be $30 \mathrm{~mol} \% \mathrm{Li}$ and 70 mol\% $\mathrm{Bi}$, which corresponds to a mixture of $\mathrm{Li}_{3} \mathrm{Bi}(\mathrm{s})$ and $\mathrm{Bi}(\mathrm{l})$ as per the $\mathrm{Li}-\mathrm{Bi}$ phase diagram. The cell exhibited stable cycling performance over 1,000 charge/discharge cycles (shown in Fig. 4). The performance parameters are summarized in Table 1. During the initial cycles, a capacity of 0.108 Ah was observed, which indicates 93\% lithium utilization. Then the discharge capacity increased slowly to achieve $0.1087 \mathrm{Ah}$, which is attributed to the better wetting of liquid lithium on the negative current collector at the end of $100^{\text {th }}$ cycle. More importantly, no capacity decay was observed during $100^{\text {th }}$ to $700^{\text {th }}$ cycles, and $96 \%$ capacity retention was found after 1000 cycles, which corresponds to a very small capacity decay of $0.004 \%$ per cycle. The calculated round-trip coulombic efficiency was $99.7 \%$ and voltage efficiency was $72 \%$, leading to an overall energy efficiency of $70 \%$. 


\subsection{Post mortem investigation}

The post-mortem cross sections of Bi electrode from the three-electrode experiment, which were cooled down in different states of charge, are shown in Fig. 5(a). It can be seen that the solid intermetallic ( $\mathrm{Li}_{3} \mathrm{Bi}$, according the $\mathrm{Li}-\mathrm{Bi}$ phase diagram) forms a layer at the top of the $\mathrm{Bi}$ electrode during discharge. A freshly cut surface of $\mathrm{Li}_{3} \mathrm{Bi}$ or one that has been polished in an oxygen free environment has a metallic luster, but turns black upon exposure to air. Below the intermetallic a bright layer can be seen which is a solid solution of Li in Bi. Grey spots are seen dispersed throughout the solid solution which is phase separated $\mathrm{Li}_{3} \mathrm{Bi}$ formed during the cool down from cell operating temperature to room temperature due to reduced solubility of $\mathrm{Li}$ in $\mathrm{Bi}$.

During charging, the intermetallic layer gradually reduces in thickness as the compound decomposes and $\mathrm{Li}$ subsequently de-alloys from the molten $\mathrm{Bi}$. At the end of the charging process the system is restored to an all-liquid state. A similar pattern is observed during the charging and discharging of the $10 \mathrm{~cm}$ cell, which is shown in Fig. 5(b).

\subsection{Cell capacity scale-up}

\section{$3.4 .110 \mathrm{~cm}$ diameter cell}

In order to investigate the scalability of the system, two prototypes with approximately $40 \times$ and $100 \times$ capacity of the $1.2 \mathrm{~cm}$ dia. prototype were assembled. Details regarding the cell construction, dimensions, and electrode masses are listed in Table S1. A schematic of the cell construction and pictures of fully assembled cells are shown in Fig 2(b).

The $10 \mathrm{~cm}$ diameter prototype was galvanostatically cycled at $0.3 \mathrm{~A} \mathrm{~cm}^{-2}$ (17 A, C/3 rate). The charge and discharge potential time lines for the $1^{\text {st }}, 10^{\text {th }}, 50^{\text {th }}$, and $100^{\text {th }}$ cycles are shown as a function of the cell capacity in Fig. 6(a). No significant change in the charge time line is observed as a function of cycle number. The discharge time line has risen gradually over time. A 
corresponding increase in the voltage and energy efficiencies is seen as a result of the lower hysteresis shown in Fig. 6(b). The estimated theoretical capacity of the cell was 53.68 Ah, and according to the cell performance this represents a Li utilization of $92 \%$.

The coulombic efficiency of the cell was around $99 \%$ throughout its service lifetime as can be seen in Fig. 6(b). As with all other $10 \mathrm{~cm}$ dia. Li\|Bi cells, it was observed that the better wetting of $\mathrm{Li}$ on the negative current collector over the initial cell cycling leads to a gradual increase in the discharge capacity, a decrease in the charge capacity, and a corresponding increase in the coulombic efficiency. At some point, they reach stable values. In addition, no capacity fade was found after 100 cycles. At a rate of C/3 these represent about a month-long test.

It can be anticipated that under actual field operation conditions of a self-heated cell stack, the temperature is likely to fluctuate depending on the rate of charge or discharge. In a rare but not unimaginable event of the failure of the battery management system the stack may also cool down to room temperature. To evaluate the system robustness under temperature changes, the cell was allowed to cool to room temperature during cell cycling. After the cool-down the cell was reheated to the operating temperature and cycling was resumed. The results from the post cool-down cycling are shown in Fig. 6(b). It can be seen that the coulombic efficiency (99\%) and energy efficiency (60\%) were exactly the same as that before cool-down. The discharge capacity was also unaffected.

\section{$3.4 .215 \mathrm{~cm}$ diameter cell}

In order to evaluate the cycling performance at an even larger scale, $15 \mathrm{~cm}$ dia. cells were fabricated and galvanostatically cycled at $0.3 \mathrm{~A} \mathrm{~cm}^{-2}(50 \mathrm{~A})$, which also corresponds to a $\mathrm{C} / 3$ rate. The cell performance results are given in Table 1. A discharge capacity of 134.7 Ah was observed 
which corresponds to a $\mathrm{Li}$ utilization of $94 \%$. This value is slightly higher than the values obtained in smaller cells. It can be seen in Fig. 7 that after a few initial cycles the capacity does not change for over three hundred cycles, which represents testing over three months. The average coulombic efficiency over 300 cycles was $99 \%$ and energy efficiency was $70 \%$, as can be seen in Fig. 7.

The performance and materials costs for cells of three different sizes are summarized in Table

2. For commercial applications the materials costs appear somewhat high $\left(\$ 220-242 \mathrm{kwh}^{-1}\right)$ but are expected to decrease with the reduction in the thickness of the electrolyte and optimization of the cell configuration.

\section{Conclusion}

Alloying and de-alloying of $\mathrm{Li}$ with the $\mathrm{Bi}$ positive electrode involves a transition from a homogeneous liquid to a heterogeneous mix comprising solid over liquid. Li-ion transport in the solid intermetallic phase is fast and does not have an observable impact on the cell voltage. Furthermore, the formation of the solid phase during discharge is fully reversible, and pristine all-liquid $\mathrm{Bi}$ is restored after every charge. As a result, the cell cycles with almost no loss of capacity. The scalability and overall robustness of this LMB chemistry were demonstrated by the operation of cells with minimal changes in design spanning a range of over $10000 \times$ the capacity of the three-electrode setup and over $100 \times$ the capacity of the $1.2 \mathrm{~cm}$ prototype. 


\section{Acknowledgments}

The financial support of the US Department of Energy, Advanced Research Projects Agency-Energy (Award No. DE-AR0000047) and TOTAL, S.A. are gratefully acknowledged. We would also like to thank our friends from the MIT central machine shop, namely Andrew Gallant and Scott Spence, as without their contributions this work would not have been possible.

\section{References}

[1] B. Dunn, H. Kamath, J.M. Tarascon, Science, 334 (2011) 928-935.

[2] Z. Yang, J. Zhang, M.C.W. Kintner-Meyer, X. Lu, D. Choi, J.P. Lemmon, J. Liu, Chemical Reviews, 111 (2011) 3577-3613.

[3] M. Pasta, C.D. Wessells, R.A. Huggins, Y. Cui, Nature communications, 3 (2012) 1149.

[4] A. Manthiram, Y. Fu, Y.-S. Su, The Journal of Physical Chemistry Letters, 4 (2013) 1295-1297.

[5] J. Liu, J.-G. Zhang, Z. Yang, J.P. Lemmon, C. Imhoff, G.L. Graff, L. Li, J. Hu, C. Wang, J. Xiao, G. Xia, V.V. Viswanathan, S. Baskaran, V. Sprenkle, X. Li, Y. Shao, B. Schwenzer, Advanced Functional Materials, 23 (2013) 929-946.

[6] D.J. Bradwell, H. Kim, A.H. Sirk, D.R. Sadoway, Journal of the American Chemical Society, 134 (2012) 1895-1897.

[7] H. Kim, D.A. Boysen, J.M. Newhouse, B.L. Spatocco, B. Chung, P.J. Burke, D.J. Bradwell, K. Jiang, A.A. Tomaszowska, K. Wang, W. Wei, L.A. Ortiz, S.A. Barriga, S.M. Poizeau, D.R. Sadoway, Chem Rev, 113 (2013) 2075-2099.

[8] A.S. Dworkin, H.R. Bronstein, M.A. Bredig, J. Phys. Chem., 66 (1962) 572-573. 
[9] M.A. Bredig, in, Oak Ridge National Laboratory, TN, 1963.

[10] E.J. Cairns, H. Shimotake, Science, 164 (1969) 1347-1355.

[11] H. Shimotake, G.L. Rogers, E.J. Cairns, I\&EC Process Design and Development, 8 (1969) 51-56.

[12] W. Weppner, R.A. Huggins, J. Electrochem. Soc., 125 (1978) 7-14.

[13] W. Gasior, Z. Moser, W. Zakulski, Archives of Metallurgy, 39 (1994) 355-369.

[14] H. Kim, D.A. Boysen, T. Ouchi, D.R. Sadoway, Journal of Power Sources, 241 (2013) $239-248$.

[15] H. Kim, D.A. Boysen, D.J. Bradwell, B. Chung, K. Jiang, A.A. Tomaszowska, K. Wang, W. Wei, D.R. Sadoway, Electrochimica Acta, 60 (2012) 154-162. 
Figure captions

Fig. 1 The mechanism of Li\|Bi liquid metal battery cycling (a) Li-Bi phase diagram (b) Schematic of cell during discharge showing formation of the solid $\mathrm{Li}_{3} \mathrm{Bi}$ layer

Fig. 2 (a) The three-electrode experimental set-up for electrochemical characterization of the $\mathrm{Li} \| \mathrm{Bi}$ system (b) Schematic of the construction of a Li\|Bi cell

Fig. 3 Electrochemical characterization of $\mathrm{Li}\|\mathrm{LiCl}-\mathrm{LiF}\| \mathrm{Bi}$ liquid metal battery discharging at different current densities. $\mathrm{T}=550^{\circ} \mathrm{C}$.

Fig. 4 Full cell cycling performance for $1.2 \mathrm{~cm}$ dia. Li $\|\mathrm{LiCl}-\mathrm{LiF}\| \mathrm{Bi}$ cell, 0.115 Ah theoretical capacity, at $0.3 \mathrm{~A} \mathrm{~cm}^{-2} . \mathrm{T}=550^{\circ} \mathrm{C}$. Dependence of discharge capacity, coulombic efficiency, and energy capacity on cycle number. Coulombic efficiency of $99.9 \%$ and only $4 \%$ capacity loss after 1000 cycles.

Fig. 5 Cross-sections of Bi positive electrode at different depths of discharge (a) $1.2 \mathrm{~cm}$ dia. cell (b) $10 \mathrm{~cm}$ dia.cell

Fig. 6 Full cell cycling performance for $10 \mathrm{~cm}$ dia. Li $\|\mathrm{LiCl}-\mathrm{LiF}\| \mathrm{Bi}$ cell, $54.7 \mathrm{Ah}$ theoretical capacity, at $0.3 \mathrm{~A} \mathrm{~cm}^{-2} \cdot \mathrm{T}=550^{\circ} \mathrm{C}$. (a) Charge and discharge curves at different cycle number (b) Dependence of discharge capacity, coulombic efficiency, and energy capacity on cycle number.

Fig. 7 Full cell cycling performance for $15 \mathrm{~cm}$ dia. Li||LiCl-LiF||Bi cell, 143.25 Ah theoretical capacity, at $0.3 \mathrm{~A} \mathrm{~cm}^{-2} . \mathrm{T}=550^{\circ} \mathrm{C}$. 


\section{LIST OF TABLES}

Table 1. Physical properties of electrodes and electrolytes

Table 2. Cell performance results and materials costs for the three different size cells

Table 1. Physical properties of electrodes and electrolytes

\begin{tabular}{llll}
\hline Material & Component & Melting & Density \\
& & temp. $\left({ }^{\circ} \mathrm{C}\right)$ & $\left(\mathrm{g} . \mathrm{cm}^{-3}\right)$ \\
\hline Lithium & Anode & 181 & 0.51 \\
$\mathrm{LiCl}-\mathrm{LiF}(30: 70)$ & Electrolyte & 501 & 1.8 \\
Bismuth & Cathode & 271 & 10.05 \\
$\mathrm{Li}_{3} \mathrm{Bi}$ & Cathode (Dch) & 1130 & 5.06 \\
\hline
\end{tabular}

Table 2. Cell performance results and materials costs for the three different size cells

\begin{tabular}{|c|c|c|c|c|c|c|c|c|c|c|}
\hline $\begin{array}{c}\text { Cell diameter } \\
/ \mathbf{c m}\end{array}$ & $\begin{array}{r}Q_{\mathrm{d}} \\
/ \mathrm{Ah}\end{array}$ & $\begin{array}{c}\boldsymbol{E}_{\boldsymbol{d}} \\
/ \mathrm{Wh}\end{array}$ & $\begin{array}{l}V_{\text {nom }} \\
/ \mathrm{V}\end{array}$ & $\begin{array}{l}\eta_{\mathrm{c}} \\
1 \%\end{array}$ & $\begin{array}{l}\eta_{\mathrm{E}} \\
1 \%\end{array}$ & $\begin{array}{c}F \\
1 \% \\
\mathrm{cyc}^{-1}\end{array}$ & & $\begin{array}{c}\text { Energy Cost } \\
\qquad / \$ \mathbf{k W h}^{-1}\end{array}$ & & $\begin{array}{c}\text { Power Cost } \\
\qquad / \$ \mathbf{k W}^{-1}\end{array}$ \\
\hline & & & & & & \multicolumn{5}{|c|}{ Electrode Electrolyte Total } \\
\hline $1.2 \mathrm{~cm}$ & 0.11 & 0.36 & 0.62 & 99 & 70 & 0.004 & 154 & 66 & 220 & 112 \\
\hline $10 \mathrm{~cm}$ & 48.8 & 26.84 & 0.55 & 99 & 65 & 0 & 169 & 62 & 231 & 663 \\
\hline $15 \mathrm{~cm}$ & 134 & 78.73 & 0.59 & 99 & 70 & 0 & 172 & 70 & 242 & 646 \\
\hline
\end{tabular}

$\mathrm{Q}_{\mathrm{d}}$ is the discharge capacity, $\mathrm{E}_{\mathrm{d}}$ the discharge energy, $\mathrm{V}_{\text {nom }}$ the normal discharge voltage, $\eta_{\mathrm{c}}$ the coulombic efficiency, $\eta_{\mathrm{E}}$ the energy efficiency, $\mathrm{F}$ the capacity fade per cycle. 
Click here to download Figure(s): 20140830 Figures revised r.docx

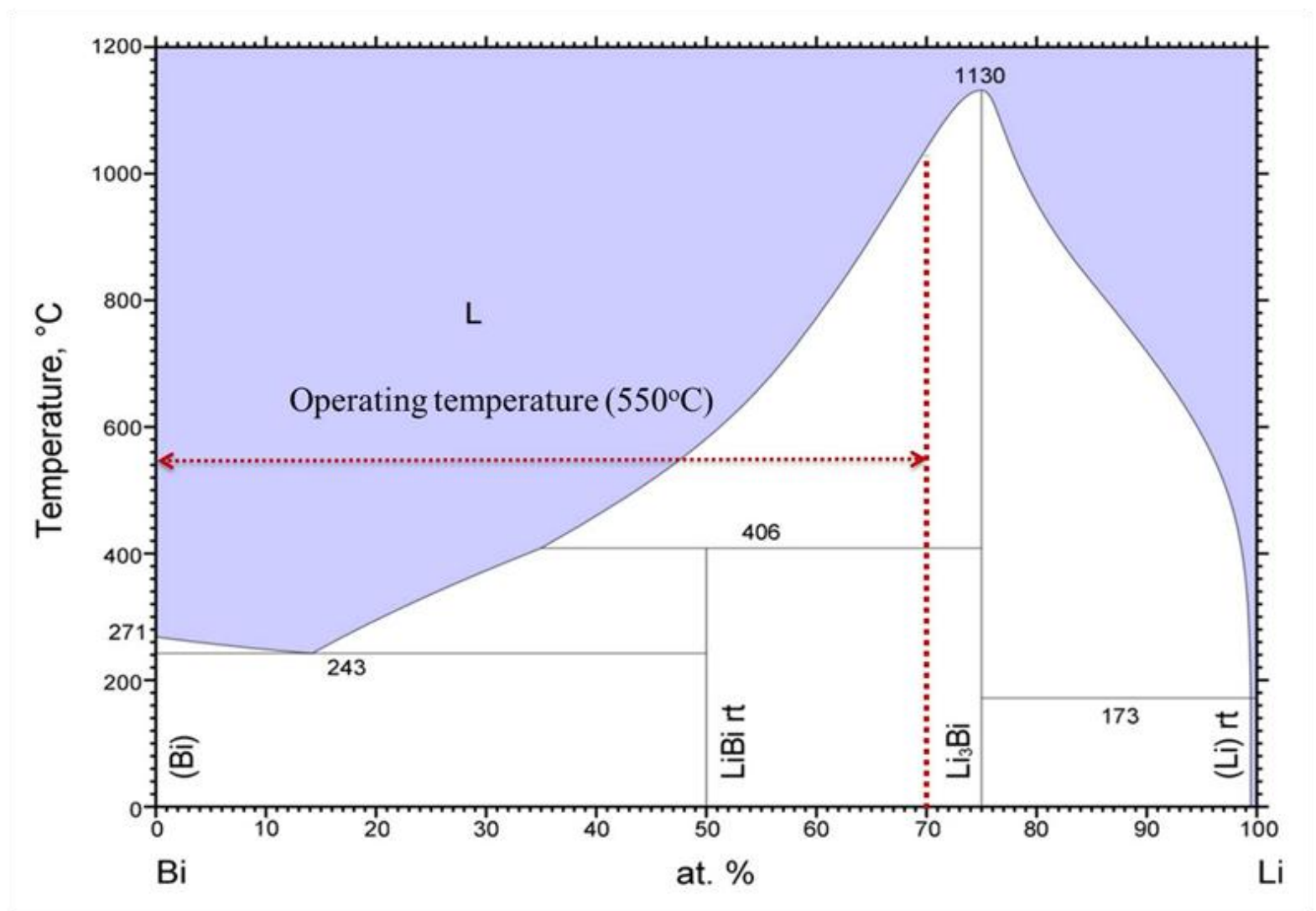

Fig 1a 

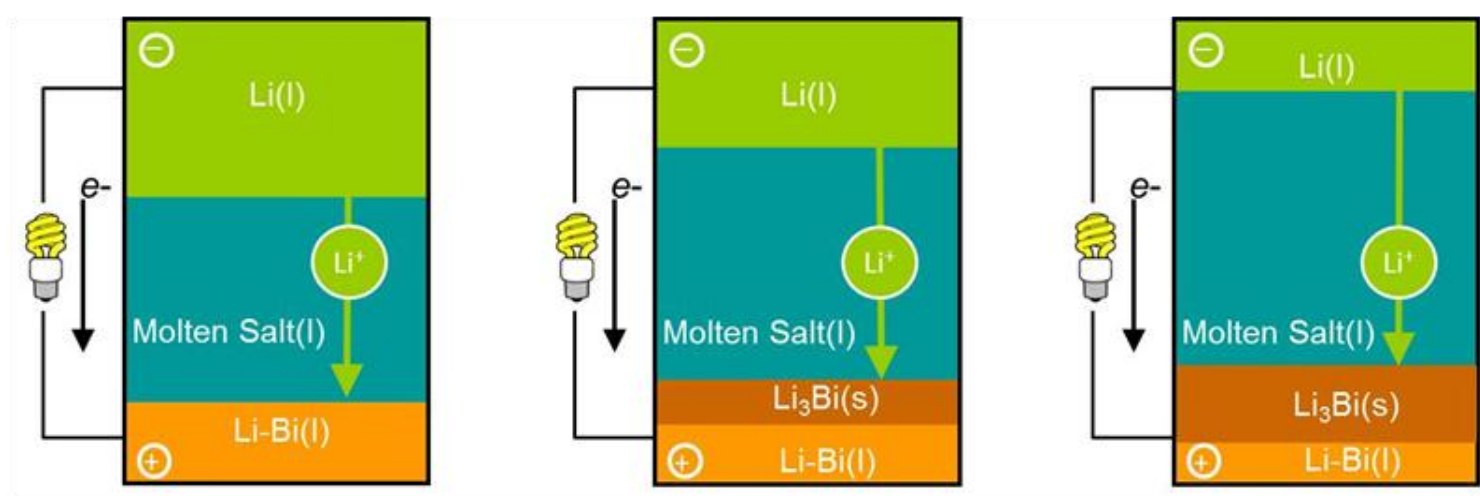

Fig 1b 


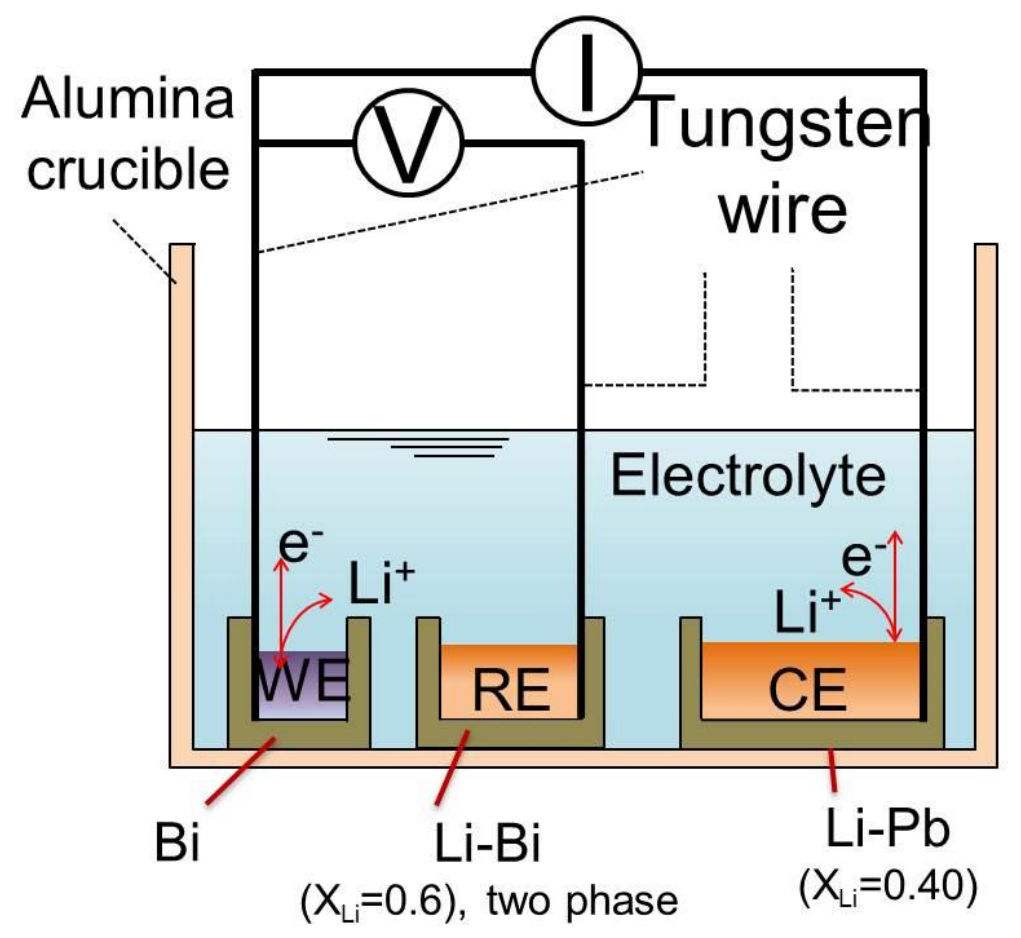

Fig 2(a) 


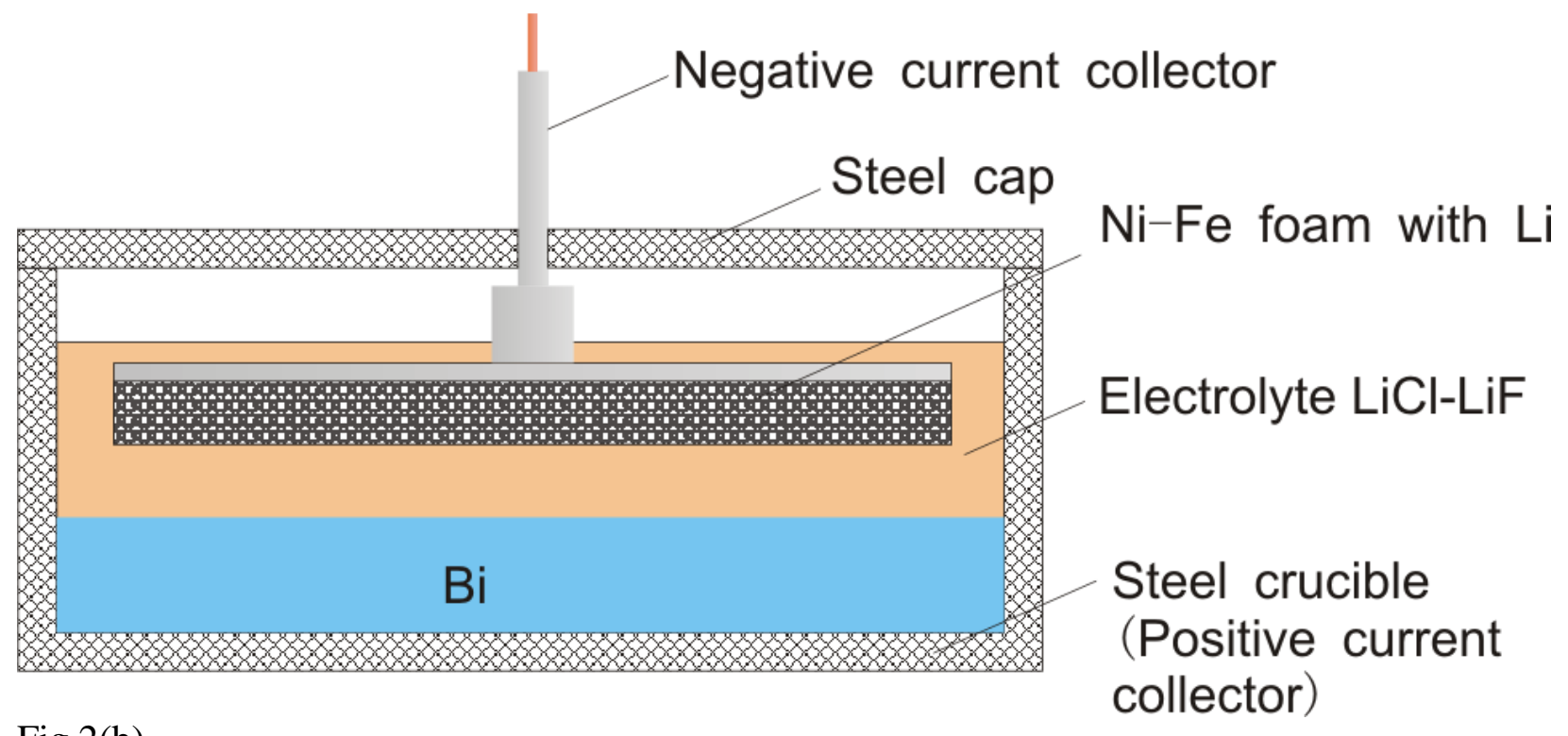

Fig 2(b) 


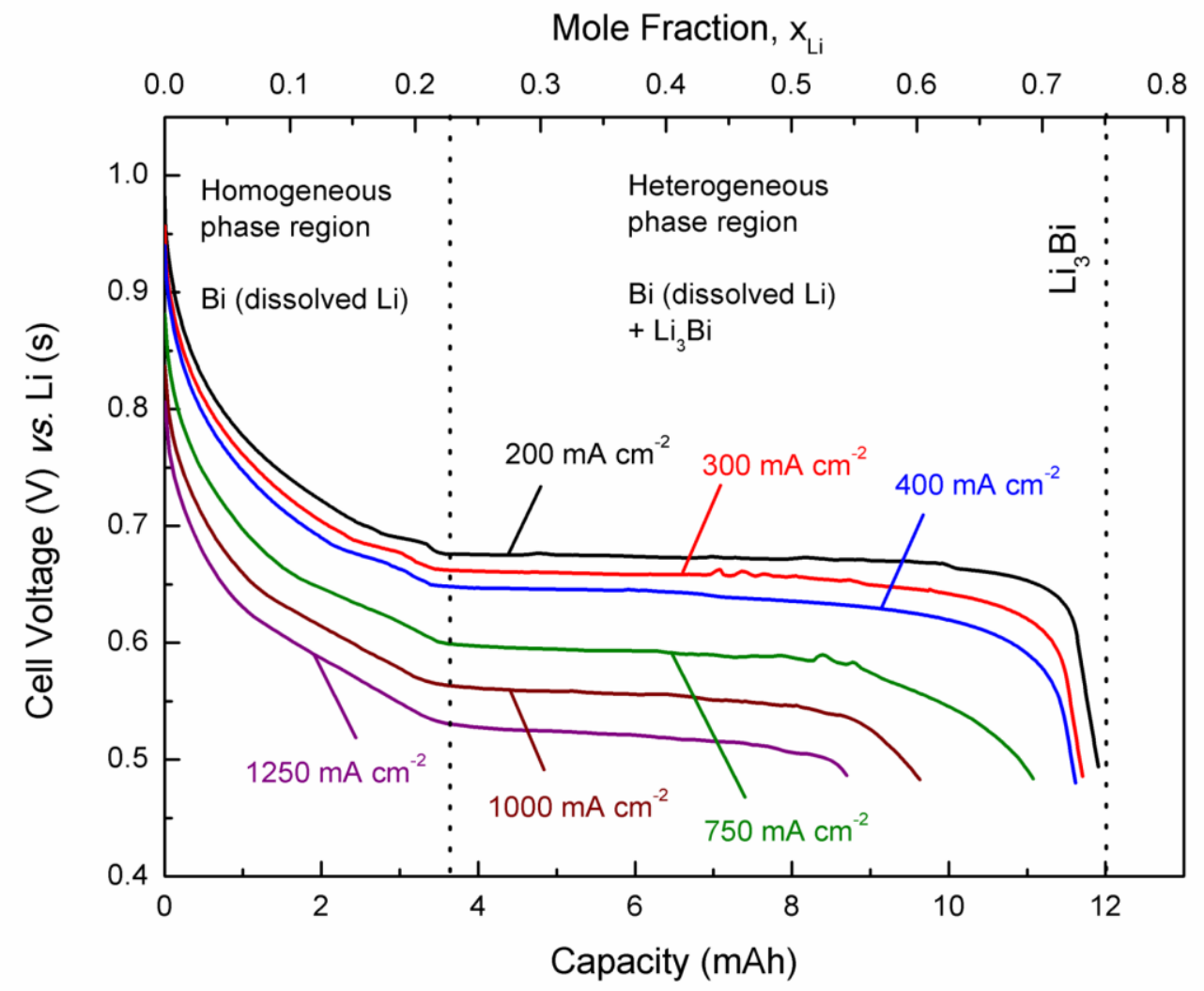

Fig 3 


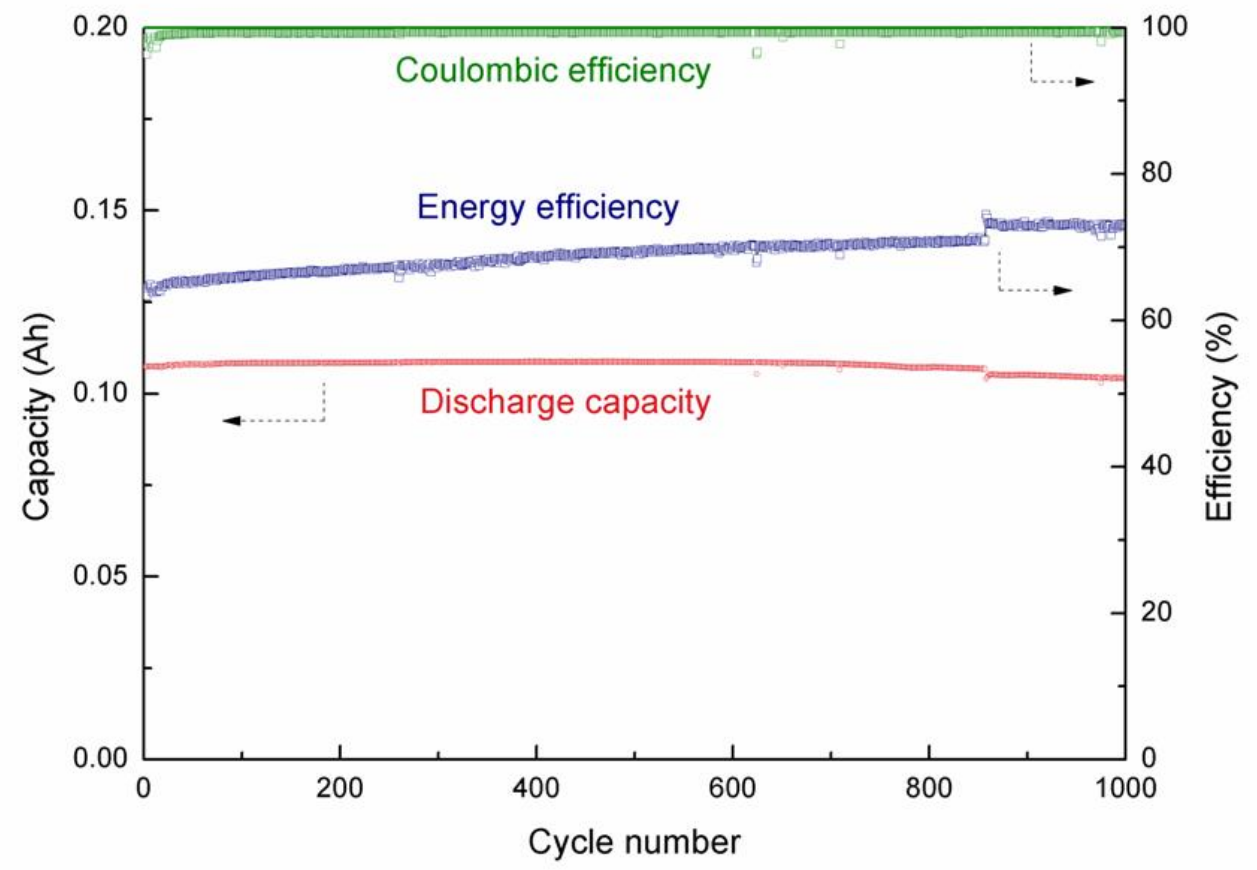

Fig 4 


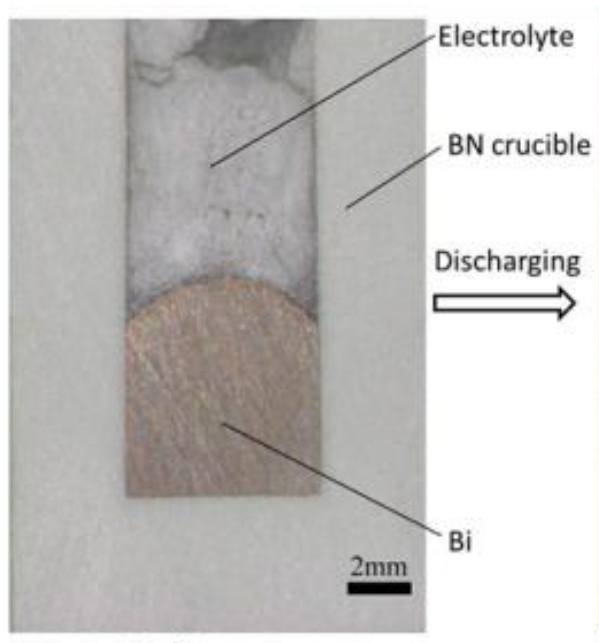

Initial State

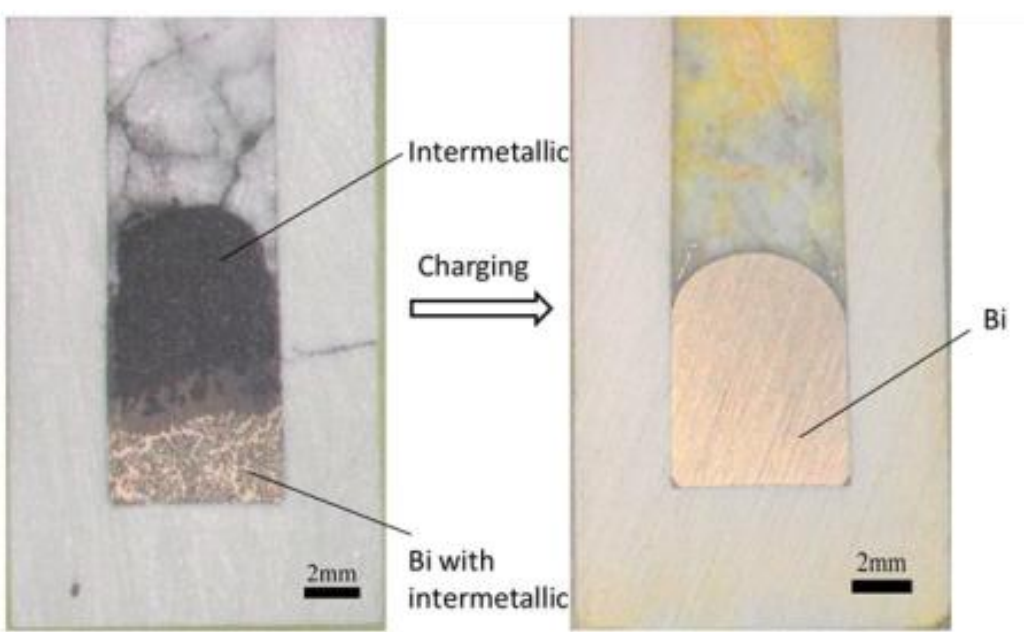

Fully Discharged State

Fig 5a 


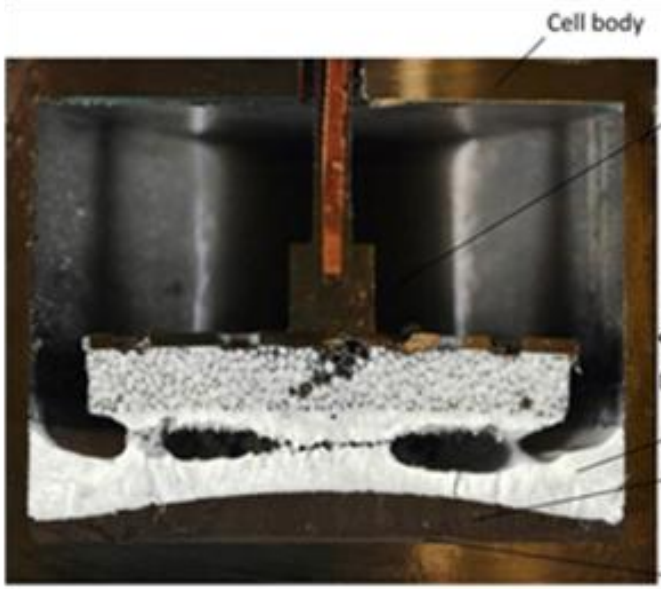

Fully Discharged State

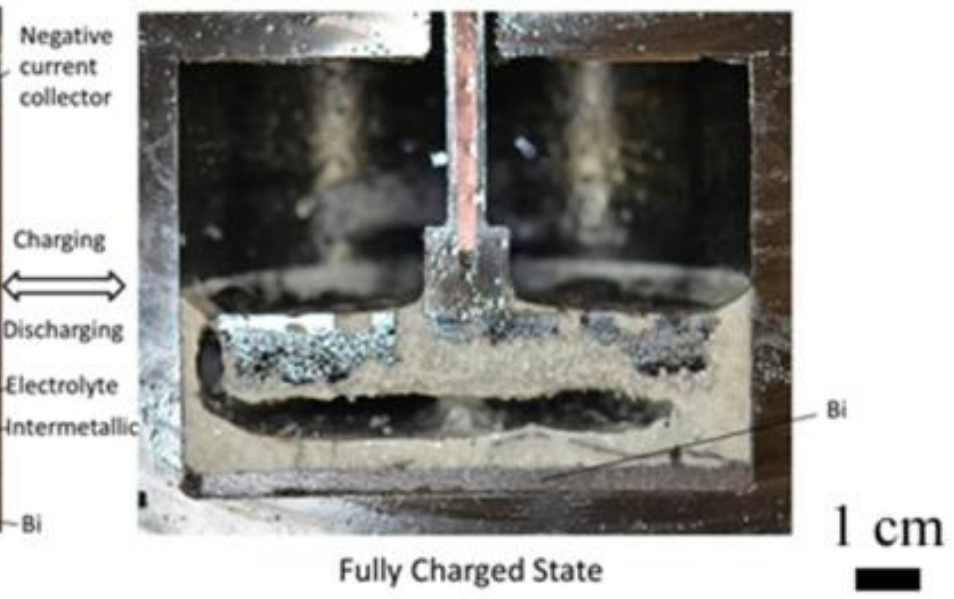

Fig $5 b$ 


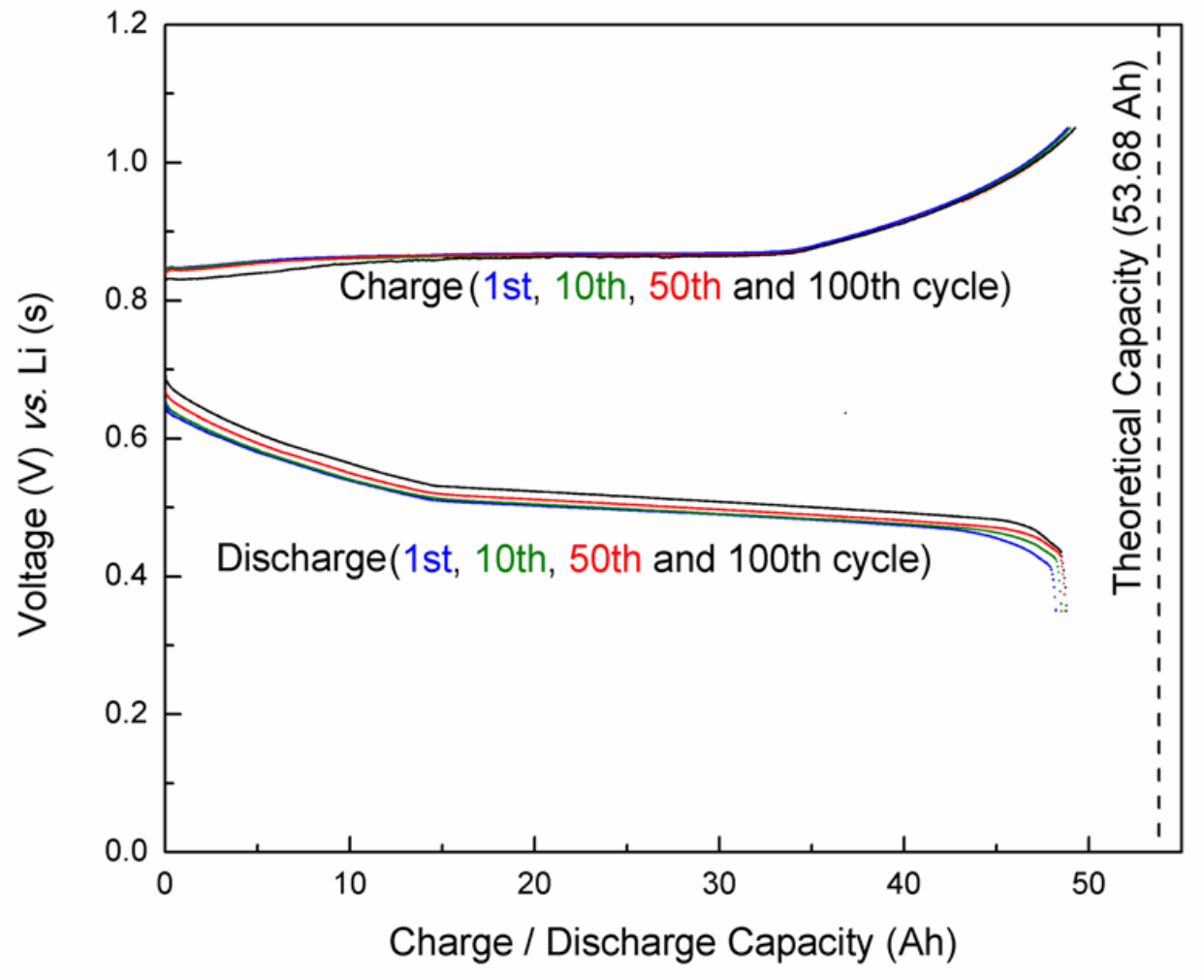

Fig 6a 


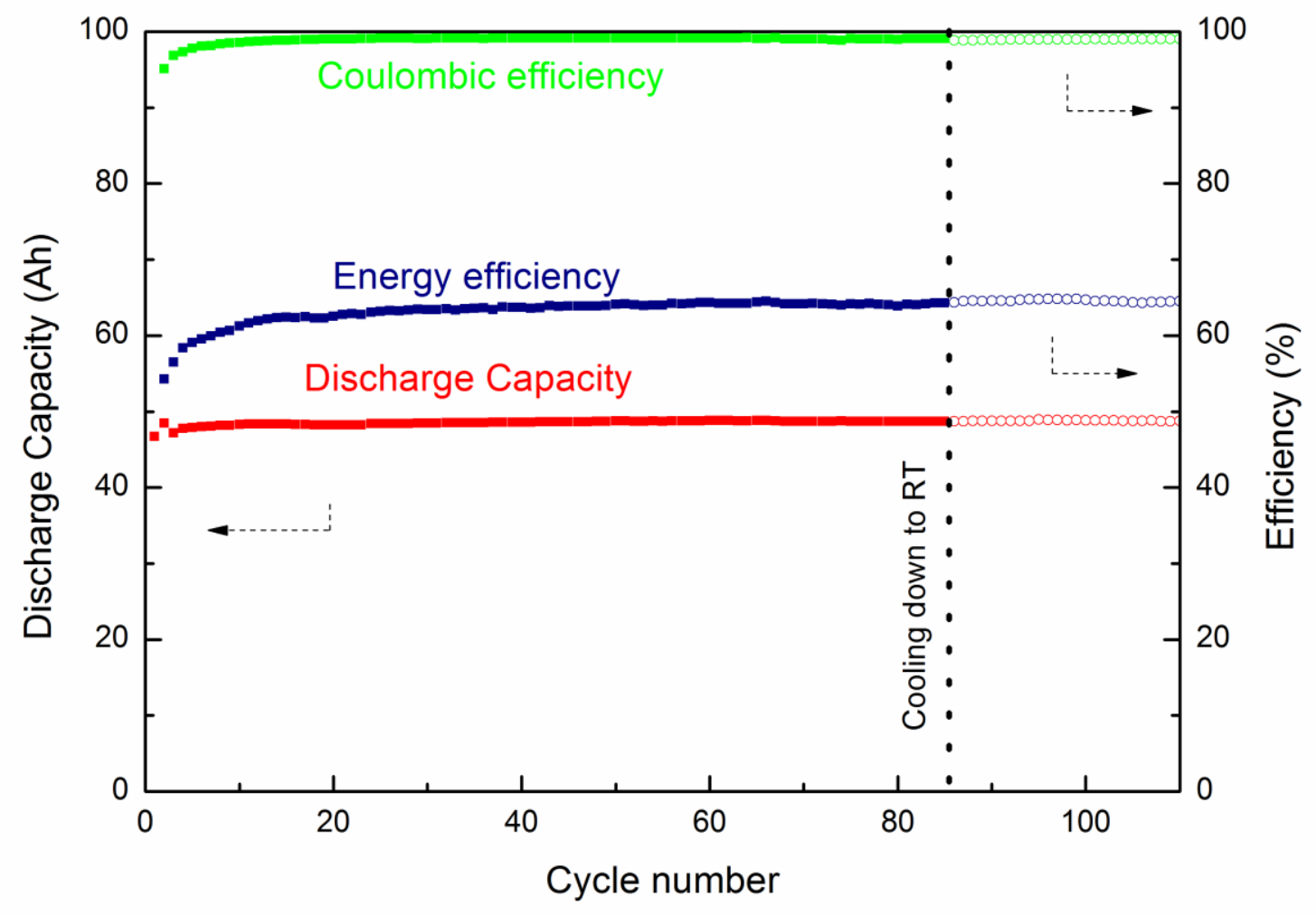

Fig $6 b$ 


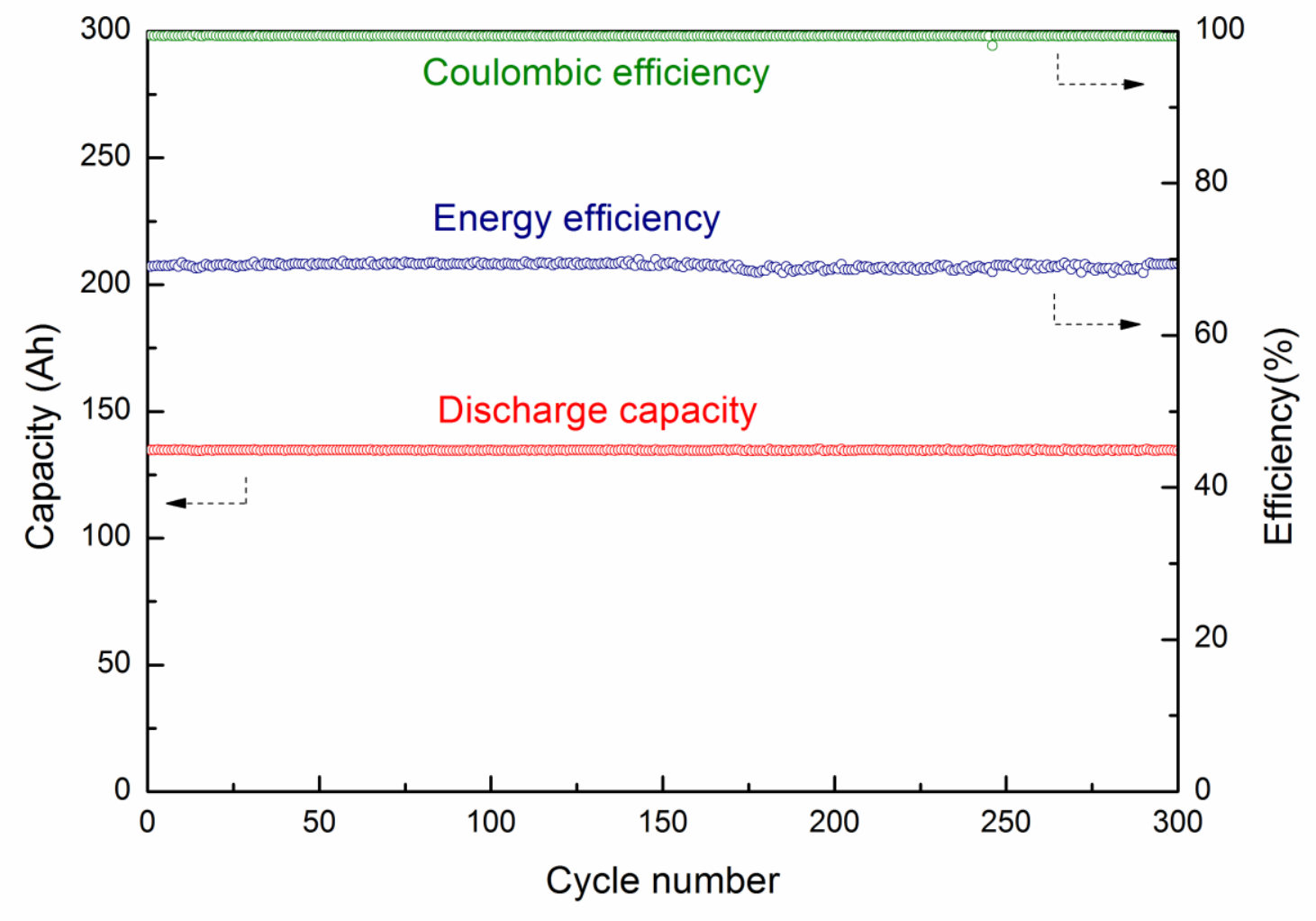

Fig 7 